\title{
Engaging with pre-teens and their parents in primary care
}

\author{
Shantha Tyler, Carolyn Mayhew-Stokes, Elizabeth Jackson
}

\begin{abstract}
Objective To encourage young people to think about health, including sexual health, and access primary care appropriately and confidently.

Concept To engage with young people before they become teenagers. This is a single introductory session for 10-year-olds with their parents. The partly structured evening is held in the surgery after it closes for other business. It includes discussion about puberty, relationships and any other health matters raised by the participants. There is an introduction to the idea of patient confidentiality.
\end{abstract}

Results About one-third of the invited 10-year-olds attended. Separating the genders improved attendance. Feedback suggested that young people increased their knowledge of puberty. They were more confident approaching health care staff for sexual health advice at the dedicated Young Person's Clinic or at normal surgery. Parents reported that their children talked more openly about relationships and sex following the session.

Conclusion A dedicated evening for pre-teens with their parents is worthwhile in primary care.

Keywords confidentiality, pre-teens, primary care, puberty

J Fam Plann Reprod Health Care 2009; 35(1): 38-40

(Accepted 7 June 2008)

\section{Introduction}

Teenage pregnancy and issues around sexual health have been at the forefront of government health policy for young people for a number of years. The Teenage Pregnancy Strategy of $1999^{1}$ set out a national agenda to tackle the issues of high teenage pregnancy rates. This strategy encouraged professionals to offer more advice and support for parents to help them talk to their children about relationships and sex. It also advised that a new emphasis be placed on ensuring young men receive information on sex and relationship matters. It set a goal to halve the under-18 conception rate by $2010 .^{1}$

Research has shown that more than a quarter of young people have had sex before they reach the age of 16 years. ${ }^{2}$ Young people aged under 16 years are the group least likely to use contraception, and concern about confidentiality remains the biggest deterrent to seeking advice. Publicity about the right to confidentiality is an essential element of an effective contraception and sexual health service. ${ }^{2}$ An educational session targeted at 10-year-olds with their parents was created in order to address this issue. This is an introductory session dealing with puberty, confidentiality and information about accessing further services, including the weekly Young Person's Clinic (YPC) when required.

This article is presented as a proof of concept that approaching young people in primary care before they start having sex is both feasible and worthwhile.

\section{Background}

The Calow and Brimington Practice is a small one with a population of 6000 patients. In order to make all general health services including sexual health, provision of condoms and complete family planning services readily available to young people, a YPC has been part of the service offered by the surgery for approximately 18 years. These dedicated sessions (for 12-22-year-olds) run every

Calow and Brimington Practice, Brimington Medical Centre, Brimington, Chesterfield, UK

Shantha Tyler, MBBS, FP Cert, General Practitioner

Carolyn Mayhew-Stokes, RGN, RHV, Health Visitor

Elizabeth Jackson, SRN, RCN Dip Sexual Health, Practice Nurse

Correspondence to: Dr Shantha Tyler, Calow and Brimington Practice, Brimington Medical Centre, Foljambe Road, Brimington, Chesterfield S43 1DD, UK. E-mail: shantha.tyler@nhs.net

\section{Key message points \\ - The sessions were equally successful for parents with boys as for parents with girls. \\ - The evenings gave opportunities for parents and their children to learn more about and discuss puberty, relationships and other age-appropriate health matters. \\ - The concept of patient confidentiality was introduced to children and parents. \\ - The availability of a weekly young person's clinic with access to contraceptive care was publicised.}

Wednesday afternoon. The sessions start at $3.30 \mathrm{pm}$ to allow young people to come, with or without their parents, straight after school. However, it was apparent that the unwanted and unplanned pregnancy rate of teenagers in the area was not falling, and indeed some young people only came to the YPC once they were pregnant.

The pre-teens evenings were seen as a possible solution. Discussions prior to starting these sessions focused around the ideas that have since been identified as crucial to good practice by Kane et al. including acceptability of service, accessibility of service, appropriateness of advertising strategy, degree of confidentiality, extent of follow-up/outreach activities and quality/quantity of information imparted at services. ${ }^{3}$

\section{Staff credentials}

The health visitors who set up the initial sessions are both family planning trained ENB (English National Board) 900 as well as RHV (Registered Health Visitor). There has been close collaboration with school nurses, who currently help to provide sex and relationship education in local schools. The present health visitor has no specific family planning qualification, but has RNMH, RGN, RHV as well as BA (Hons) in Public Health nursing, health visiting and combined studies. She is also a nurse prescriber. The practice nurse has SRN and obtained the JBCNS (Joint Board Clinical Nurse Studies) 900 family planning certificate in 1980 and has worked in contraception and sexual health clinics since then, taking the RCN diploma in sexual health in 2005. The lead general practitioner involved has the Family Planning Certificate and has been a member of the local young people's sexual health strategy group. She has also attended regular updates in family planning and sexual health. 


\section{Methods}

The evenings are aimed at children who have just attained the age of 10 years and their parents or guardians. At any given time there are about 80 10-year-olds registered with this practice. All of these individuals are invited to one of the sessions.

It has been critical to get the time and date right. Invitation is by means of an attractive card addressed to the child with another card sent to the parent. The evenings are held in two large rooms in the surgery at 6-7 pm, immediately after the surgery closes for other business. There are two evening sessions (one each for girls and boys) in April and another two in September, avoiding holidays. Support from the general practice in the form of finance, premises and administration has been crucial to the success of this venture.

Between 1998 and 2002, girls and boys were invited to attend with their parents. There was a failure to engage with the boys, but girls and their mothers attended. The evening consisted of a video followed by discussion (as detailed below). In 2002, the pre-teens evenings ceased when key staff left due to retirement or moving elsewhere.

The evenings were restarted in 2004 by the present authors. Ways of engaging with boys as well as girls with their parents were re-explored. Some children had informed us that talks at school had been embarrassing as these were given to mixed sex groups. Fear of being laughed at had limited the children's ability to ask questions. Consequently it was decided that separate gender evenings would be more appropriate.

\section{Content of the evening}

The evening is based around watching a video and the subsequent discussion. The Living Well 3 video produced by Channel 4 and aimed at 9-11-year-olds is used. The 15minute programme has separate sections aimed at girls and boys, and deals with the physical and emotional changes that occur in this age group. This video seemed the most appropriate one available at the time the sessions were being run.

Both parents and children watch the video together. Then the children and adults go into separate rooms: one group with the practice nurse and the other with the health visitor. This allows separate and frank discussions around any issues raised.

Some participants will have already seen the video or a similar one at school. Others, especially the girls, have already experienced some of the changes mentioned. The girls are given the opportunity to handle tampons and sanitary towels, thus allowing some of the myths around periods to be dispelled. The discussions are very informal. Other health and relationship issues are raised, for example, family and peer relationships, bullying, and general lifestyle advice on diet and exercise. The adults have a discussion around the video and are able to voice any concerns they have. Peer support is integral to these sessions.

Sexual activity is not discussed directly. It is hoped that talking about their bodies, their emotions and feelings in a direct and unembarrassed way will help individuals come to us in the future. Information is given about the drop-in YPC for 12-22-year-olds, which includes full family planning provision. Patient confidentiality ${ }^{2}$ policies of the YPC are emphasised so that parents and children are aware of these in advance of their choosing to attend.

\section{Results}

Generally, the feedback on the sessions has been positive. At first, two parents felt their children were too young to attend the sessions. Hence, the invitations were changed to include details on how parents could contact us if they have any reservations or concerns prior to the evening.

It was felt that it would be useful to get some formal feedback from the sessions to facilitate making any changes. A simple feedback questionnaire was devised for parents and children to complete following the last four sessions. Completed questionnaires have demonstrated that most children felt that the session had increased their knowledge of puberty. They were now confident enough to contact staff at the surgery for more information if needed. Most of the parents commented that the evening gave them an opportunity to talk openly and naturally with their children. Parents also said that their children talk to them following the evening, immediately following the separate group sessions, or on their way home. One male, single parent was very pleased to have the opportunity to discuss female puberty with the facilitators of the sessions. Having been very unsure about female puberty, he had not known how to talk to his daughters about this matter. A child with learning disabilities attended one of the groups, thus presenting an opportunity to look at how to involve young people with learning disabilities in the sessions. Two of the parents asked for follow-up sessions suitable for children aged around 12 or 13 years.

As more people have become aware of these sessions there has been an increase in numbers attending, especially boys (Table 1). Attendance data are not available from the initial period.

All the children in the eligible age group were invited to attend, and about one-third of those invited attended. With the parents present, this made the group a good size of 18-20 people.

The cohort who took part in the early sessions has reached the age of at least 16 years over the past 5 years. In order to maintain confidentiality, the names of the youngsters who attended have not been recorded and so we are unable to follow up the group to see whether their behaviour has been altered as a result of their attendance at the sessions.

One of the study objectives was to decrease the unwanted teenage pregnancies in our practice population. Although the pregnancy rates - which are low compared to the rest of Derbyshire - have changed little, the termination rates appear to have fallen. General conclusions cannot be drawn as the dataset is inevitably a small one. Furthermore, it was felt that disclosure of the actual figures was inadvisable since this might enable individual patients to be identified and cause a breach of confidentiality.

\section{Discussion}

These sessions were set up in response to rising teenage conceptions (particularly terminations) despite the existence of a dedicated YPC. Contrary to assertions that general practice is generally poor at engaging with teenagers, we feel that general practice is well placed to engage with this age group.

Table 1 Attendance figures for the pre-teens sessions held during the period 2004-2007

\begin{tabular}{llllll}
\hline Month & \multicolumn{2}{c}{ Boys $(\boldsymbol{n})$} & & \multicolumn{2}{c}{ Girls $(\boldsymbol{n})$} \\
\cline { 2 - 3 } \cline { 5 - 6 } & Invited & Attended & & Invited & Attended \\
\hline September 2004 & 28 & 2 & 15 & 5 \\
April 2005 & 14 & 5 & & 26 & 6 \\
September 2005 & 28 & 8 & & 15 & 5 \\
April 2006 & 20 & 7 & & 18 & 8 \\
September 2006 & 23 & 10 & & 20 & 8 \\
April 2007 & 22 & 7 & 24 & 8 \\
\hline
\end{tabular}


According to the Teenage Pregnancy Unit, ${ }^{4}$ any interventions and programmes are most likely to be effective if the principles outlined below are followed:

- Focus on improving contraceptive use and at least one other behaviour pattern likely to prevent pregnancy and sexually transmitted infection transmission

- Ensure interventions/programmes are long term

- Tailor services to meet local needs and target local high-risk groups

- Have clear, unambiguous messages

- Use teaching methods that allow young people to participate

- Ensure services are accessible to young people in terms of opening hours, location and level of information provided

- Ensure interventions are based on theory and have clear behavioural goals and objectives

- Use staff who have been trained and are committed to the programme and to working with young people

- Whenever possible, respect young people's confidentiality and views

- Aim for interventions to be in place before young people become sexually active

- Focus on both young women and young men

- Foster an open and communicative atmosphere for talking about sex and sexuality.

The approach of the initial pre-teen group sessions followed by a weekly YPC fulfils all the above criteria. However, consideration needs to be given to whether an extra session is needed for 13-year-olds to discuss sex and sexuality more openly.

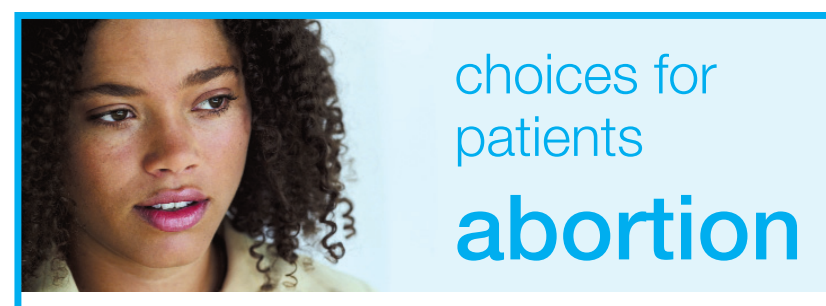

Dr Kate Worsley

Head of Medical Development - Marie Stopes International

Marie Stopes International sees over one third of all women seeking abortion services in England and Wales. As experts in this field they have pioneered and modernised abortion provision making them first choice amongst healthcare professionals. The service is always designed around the clients needs and convenience. An example of this is the recent development by the organisation of offering women the choice of having a telephone consultation where they can discuss their abortion options from the comfort of their own homes.

Medical abortion - currently one third of women between 4-9 weeks gestation having abortion choose the abortion pill. At Marie Stopes centres this has been simplified to just two visits.

Surgical abortion - women prefer a quick, convenient appointment and the majority are now choosing Marie Stopes one visit only appointments. A choice of anaesthesia is also offered by the organisation.

A dedicated 24 hour aftercare line run by a team of expert nurses offers clients all the advice and support they need.

For more information call for a Marie Stopes International GP sexual health pack containing referral guidelines and client leaflets.

08451203644

www.mariestopes.org.uk

CONTRACEPTION • HEALTH SCREENING

STERILISATION • VASECTOMY • ABORTION

\section{Conclusions}

It is worthwhile running a dedicated evening for pre-teens with their parents in a primary health care setting to offer age-appropriate health education. The sessions improved communications between parent and child, and enabled the child to understand issues of confidentiality and appropriate use of health care facilities. This approach targets the under-16-year-olds well before they are at risk of pregnancy and other high-risk behaviour.

\section{Acknowledgements}

The authors want to thank Mrs Maxine Bilton and Mr Edward Oakley, medical students at Sheffield Medical School, for proofreading the manuscript, and Mrs Karen Cousins and Mrs Ann Charles, health visitors, who originally came up with the idea of holding pre-teen group sessions and initiated these sessions in the primary care setting.

Statements on funding and competing interests

Funding None identified.

Competing interests None identified.

\section{References}

1 Department of Health. Teenage Pregnancy Strategy. London, UK: Department of Health, 1999.

2 Wellings K, Nanchahal K, Macdowall W, McManus S, Erens R, et al. Sexual behaviour in Britain: early heterosexual experience. Lancet 2001; 358: 1843-1850.

3 Kane R, Macdowall W, Wellings K. Providing information for young people in sexual health clinics: getting it right. J Fam Plan Reprod Health Care 2003; 29: 141-145.

4 Teenage Pregnancy Unit. Better 'Sex and Relationships' Education: Solving the Problem. http://www.idea.gov.uk/ idk/core/page.do?pageld=8217089\&aspect=full [Accessed 14 May 2008].

\section{Lubrication ...naturally}

SYLK natural personal lubricant for the alleviation of atrophic vaginitis is now included within the NHS Drug Tariff Part IX and available on an FP10.

Adopted and endorsed by a multiprofessional group investigating the use of vaginal dilators following pelvic radiotherapy, as well as members of the National Committee of the

National Forum of Gynaecology

Oncology Nurses (NFGON) and other relevant groups within the NHS, SYLK:

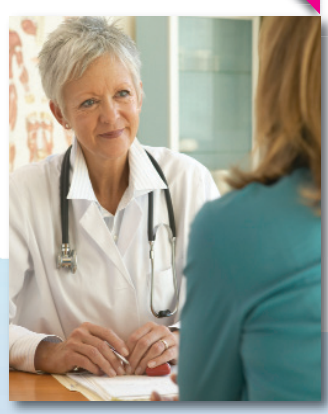

- has a non chemical base derived from an extract of the kiwi fruit plant that effectively mimics a woman's natural secretions and is the only paraben free lubricant

- has passed cytotoxicity, sensitisation and product stability tests. The pH of SYLK is controlled within 4.5 to 4.7 , to equate with the vaginal environment

- is a class 1 medical device available in one $40 \mathrm{~m}$ size, sufficient for up to 150 applications

Free samples and consumer literature are readily available from:

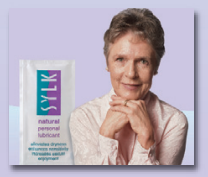
SYLK Limited FREEPOST, PO Box 340 Rickmansworth, WD3 5WD Tel: 08709506004 www.sylk.co.uk

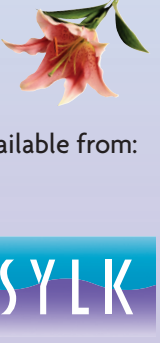

